Abstract-Piscivorous fishes, many of which are economically valuable, play an important role in marine ecosystems and have the potential to affect fish and invertebrate populations at lower trophic levels. Therefore, a quantitative understanding of the foraging ecology of piscivores is needed for ecosystem-based fishery management plans to be successful. Abundance and stomach contents of seasonally co-occurring piscivores were examined to determine overlap in resource use for Summer Flounder (Paralichthys dentatus; 206-670 $\mathrm{mm}$ total length [TL]), Weakfish (Cynoscion regalis; 80-565 $\mathrm{mm}$ TL), Bluefish (Pomatomus saltatrix; 55-732 mm fork length [FL]), and Striped Bass (Morone saxatilis; 422$920 \mathrm{~mm}$ FL). We collected samples from monthly, fishery-independent trawl surveys conducted on the inner continental shelf $(5-27 \mathrm{~m})$ off New Jersey from June to October 2005. Fish abundances and overlaps in diet and habitat varied over this study period. A wide range of fish and invertebrate prey was consumed by each species. Diet composition (determined from 1997 stomachs with identifiable contents) varied with ontogeny (size) and indicated limited overlap between most of the species size classes examined. Although many prey categories were shared by the piscivores examined, different temporal and spatial patterns in habitat use seemed to alleviate potential competition for prey. Nevertheless, the degree of overlap in both fish distributions and diets increased severalfold in the fall as species left estuaries and migrated across and along the study area. Therefore, the transitional period of fall migration, when fish densities are higher than at other times of the year, may be critical for unraveling resource overlap for these seasonally migrant predators.

Manuscript submitted 24 October 2012. Manuscript accepted 26 August 2013. Fish. Bull. 111:352-369.

doi: $10.7755 /$ FB.111.4.5

The views and opinions expressed or implied in this article are those of the author (or authors) and do not necesarily reflect the position of the National Marine Fisheries Service, NOAA.

\title{
Habitat and diet overlap of 4 piscivorous fishes: variation on the inner continental shelf off New Jersey
}

\author{
Mark J. Wuenschel (contact author) ${ }^{1}$ \\ Kenneth W. Able ${ }^{1}$ \\ James M. Vasslides' \\ Donald M. Byrne ${ }^{2 *}$ \\ Email address for contact author: mark.wuenschel@noaa.gov \\ ${ }^{1}$ Marine Field Station \\ Rutgers University \\ 800 c/o 132 Great Bay Boulevard \\ Tuckerton, New Jersey 08087-2004 \\ Present address for contact author: Northeast Fisheries Science Center \\ National Marine Fisheries Service, NOAA \\ 166 Water St. \\ Woods Hole, Massachusetts 02543 \\ ${ }^{2}$ New Jersey Department of Environmental Protection \\ Nacote Creek Research Station \\ P.O. Box 418 \\ Port Republic, New Jersey 08241 \\ * Deceased
}

Predator species and their interactions with prey and other predator species play an important role in determination of the structure and function of ecosystems (Schmitz, 2007; Braga et al., 2012)—an especially important concern because populations of many predators have declined in abundance (Myers and Worm, 2003; Heithaus et al., 2008). In marine ecosystems, piscivorous fishes have the potential to affect fish and invertebrate populations at lower trophic levels. In some cases, direct removals of prey resources by piscivorous fishes have been shown to rival or even exceed the removals by commercial fisheries (Buckel et al., 1999c; Overholtz et al., 2000; Overholtz and Link, 2007). Therefore, fish trophic ecology is relevant to several aspects of fisheries management (Link, 2002). With the general move toward multispecies and ecosystem-based approaches to fisheries management, there is a need for more comprehensive information on food web structure, interspecific trophic interactions, and predator movements (Andrews and Harvey, 2013).

In temperate zones, many coastal marine fishes undergo large-scale seasonal and ontogenetic shifts in their spatial distribution. Examples from the east coast of the United States include species that migrate north to New England in summer and south to the Carolinas in winter (e.g., Striped Bass [Morone saxatilis] and Bluefish [Pomatomus saltatrix]) and species that move inshore in summer and offshore in winter (e.g., Summer Flounder [Paralichthys dentatus] and Weakfish [Cynoscion regalis]) (Able and Fahay, 2010). Further, many temperate, estuarine-dependent species in the Middle Atlantic Bight leave estuaries in the fall of their first year to avoid cold winter temperatures (Able and Fahay, 1998; 2010). Many of these young-of-theyear (YOY) fishes are piscivorous and their egress from estuaries to coastal waters acts to concentrate them in time and space with other 
species or size classes, increasing the potential for both interspecific and intraspecific interactions. Interspecific competition and resource partitioning have been well documented for fish species in freshwater systems (Persson et al., 1999; Sutton and Ney, 2002; Bellgraph et al., 2008), where the potential for interactions may be greater than it is in marine systems given the closed nature of freshwater systems and fish populations. This interspecific competition and resource partitioning may apply to some degree in estuaries as well, as has been reviewed for European estuaries (Elliot and Hemingway, 2002). In contrast, because of the openness of marine populations and the ability of individuals to move great distances, interspecific competition in most marine systems likely is highly variable in time and space, making it more difficult to document and study interspecific competition in marine systems than in freshwater populations.
Summer Flounder, Weakfish, Bluefish, and Striped Bass are important commercial and recreational species in New Jersey and elsewhere on the east coast of the United States. These species co-occur seasonally and feed on similar prey, indicating potential for competitive interactions. However, studies of food habits for these species generally have focused on estuarine collections (Gartland et al., 2006; Latour et al., 2008) or have been limited to seasonal, offshore (at depths of 5-400 m) collections aggregated over multiple years (Buckel et al., 1999b, Garrison and Link, 2000a, 2000b; Link et al., 2002; Overton et al., 2008; Woodland et al., 2011). Further, most prior studies on these species typically have focused on a single (Gartland et al., 2006; Latour et al., 2008) or a pair of species (Buckel and McKown, 2002; Buckel et al., 2009). Because of the spatial and temporal variability in competitive interactions between migratory fishes, studies span-

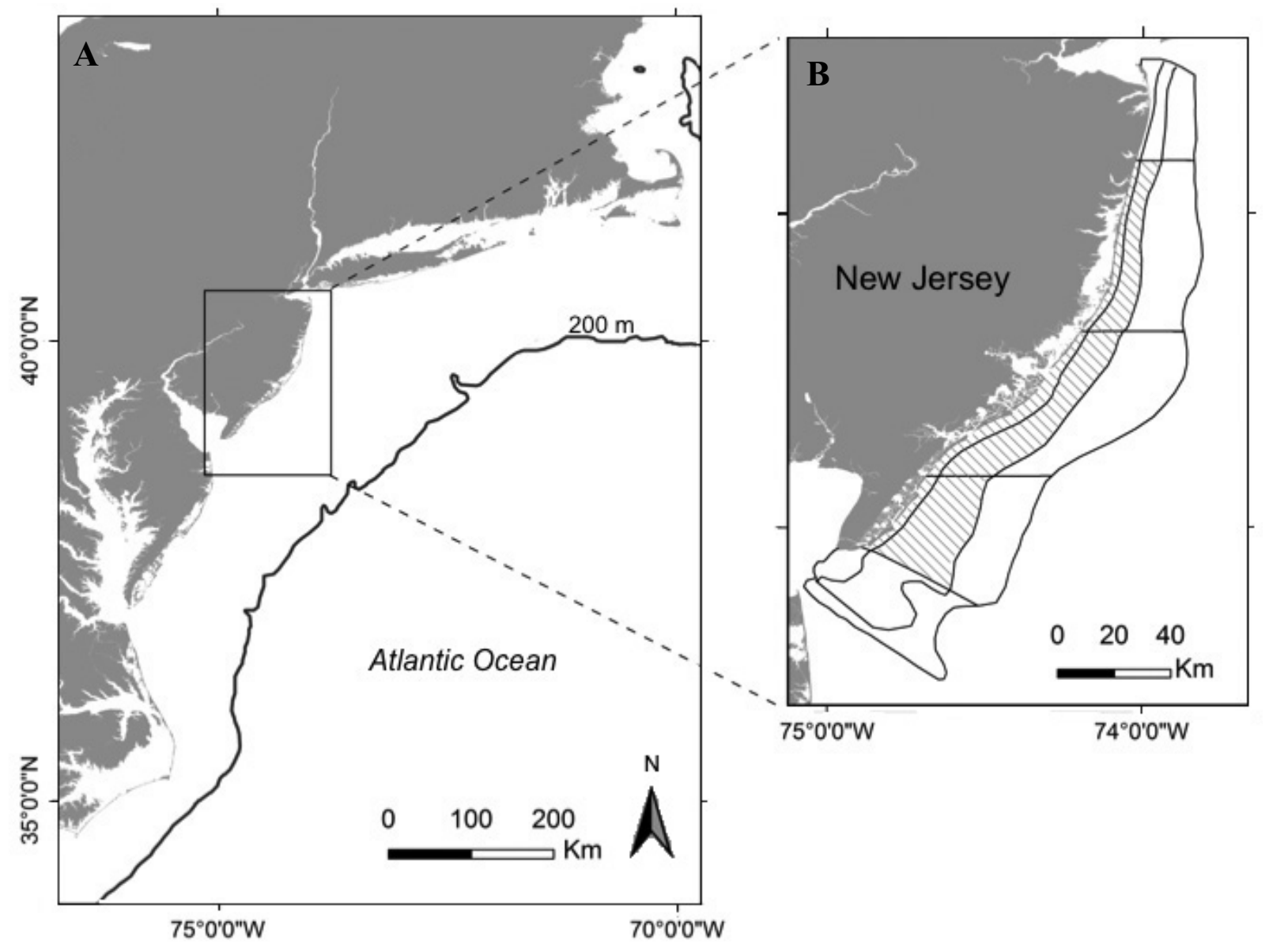

Figure 1

(A) Study area where Summer Flounder (Paralichthys dentatus), Weakfish (Cynoscion regalis), Bluefish (Pomatomus saltatrix), and Striped Bass (Morone saxatilis) were sampled in 2005 along the northeastern coast of the United States for a 5-month study of habitat and diet overlap of these 4 piscivorous fishes and (B) sample collection area off New Jersey with the 15 strata outlined (strata were defined on the basis of latitudinal boundaries and depth contours of 9, 18, and $27 \mathrm{~m}$ ). In June, August, and October, all strata were sampled. In July and September, only strata indicated with diagonal lines were sampled. 
ning multiple years, such as many of the ones listed above, potentially blur or miss finer-scale interactions that occur over shorter intervals. Therefore, to evaluate potential interactions between mobile, seasonally migratory species, information on spatial distributions and food habits is needed at finer spatial and temporal scales (Rudershausen et al., 2010). Although resource overlap among Summer Flounder, Weakfish, Bluefish, and Striped Bass has been indicated by or inferred in prior studies (Garrison and Link, 2000b), often over broad areas or time periods, a rigorous evaluation of these interactions at a more relevant ecological scale is lacking.

The objectives for this study were to compare habitat use and food habits of 4 common predators of the Middle Atlantic Bight over the course of a 5-month period of co-occurrence in nearshore (inner continental shelf) waters. The degree of overlap in both habitat and diet between different size classes of these 4 predators was quantified to determine resource overlap at a fine spatial and temporal scale.

\section{Materials and methods}

The distribution, abundance, and diet of Summer Flounder, Weakfish, Bluefish, and Striped Bass were evaluated from 20-min bottom trawls (30-m headrope, 6-mm codend liner [Byrne, 1994; Wuenschel et al.,
2012]) conducted in inner continental shelf waters of New Jersey in collaboration with the Bureau of Marine Fisheries of the New Jersey Department of Environmental Protection. Through the use of a depthstratified random sampling design, samples were taken during daylight hours at depths of 5 to $27 \mathrm{~m}$ along the New Jersey coast from the entrance of New York Harbor to the entrance of Delaware Bay (Fig. 1). The survey area was divided into 15 strata (Fig. 1) on the basis of latitudinal boundaries and depth contours (9, 18, and $27 \mathrm{~m}$; Byrne, 1994). In June, August, and October 2005, all depths and strata were sampled with 2 tows per strata, plus 1 additional tow in each of the 9 largest strata (39 tows, Table 1; see Byrne 1994 for details). In the intervening months (July and September), sampling was undertaken with a bottom trawl net, bridles, and towing cables that were identical to the ones used in June, August, and October and were fished from the same vessel (RV Seawolf, SUNY Stonybrook) used during the other months, but because of constraints on vessel time, sampling was limited to 2 or 3 tows in nearshore and mid-shore depths for all but the northernmost and southernmost strata (18 tows, July; 12 tows, September; Table 1, Fig. 1). Representative subsamples, with a mean of 8.4 (9.6 standard deviation $[\mathrm{SD}])$ per species per tow, of Summer Flounder, Weakfish, Bluefish, and Striped Bass were selected to cover the range of lengths of fish collected in a given tow for analysis of gut contents. Stomachs were re-

Table 1

Summary of samples collected in 2005 off the coast of New Jersey for this study of habitat and diet overlap of 4 piscivorous fishes. Collection month and sampling effort (numbers of tows in parentheses), numbers of fish collected, stomachs analyzed in the laboratory, and stomachs with prey in the gut for small, medium, and large Summer Flounder (Paralichthys dentatus), PdS, PdM, PdL; small, medium, and large Weakfish (Cynoscion regalis), CrS, CrM, CrL; small and large Bluefish (Pomatomus saltatrix), PsS, PsL; and Striped Bass (Morone saxatilis), Ms.

\begin{tabular}{|c|c|c|c|c|c|c|c|c|c|c|}
\hline & & PdS & PdM & PdL & $\mathrm{CrS}$ & CrM & $\mathrm{CrL}$ & PsS & PsL & $\mathrm{Ms}$ \\
\hline \multirow[t]{3}{*}{ June (39) } & Fish collected & 85 & 170 & 80 & 1 & 774 & 1 & 9 & 4 & 7 \\
\hline & Stomachs analyzed & 47 & 63 & 35 & 0 & 46 & 1 & 0 & 6 & 0 \\
\hline & Stomachs with prey & 30 & 42 & 26 & 0 & 42 & 1 & 0 & 4 & 0 \\
\hline \multirow[t]{3}{*}{ July (18) } & Fish collected & 134 & 296 & 61 & 64 & 6319 & 0 & 48 & 3 & 0 \\
\hline & Stomachs analyzed & 72 & 153 & 51 & 0 & 125 & 0 & 21 & 3 & 0 \\
\hline & Stomachs with prey & 39 & 74 & 12 & 0 & 116 & 0 & 18 & 3 & 0 \\
\hline \multirow{3}{*}{ August (39) } & Fish collected & 302 & 950 & 148 & 2587 & 4232 & 31 & 890 & 23 & 214 \\
\hline & Stomachs analyzed & 71 & 245 & 108 & 100 & 109 & 7 & 150 & 20 & 27 \\
\hline & Stomachs with prey & 64 & 178 & 62 & 99 & 84 & 5 & 105 & 17 & 11 \\
\hline \multirow[t]{3}{*}{ September (12) } & Fish collected & 29 & 783 & 116 & 17,836 & 11,752 & 189 & 2370 & 6 & 0 \\
\hline & Stomachs analyzed & 4 & 117 & 22 & 134 & 58 & 5 & 185 & 5 & 0 \\
\hline & Stomachs with prey & 3 & 74 & 8 & 96 & 45 & 5 & 147 & 2 & 0 \\
\hline \multirow[t]{3}{*}{ October (39) } & Fish collected & 12 & 192 & 31 & 9746 & 10,275 & 1786 & 616 & 70 & 123 \\
\hline & Stomachs analyzed & 6 & 134 & 26 & 172 & 93 & 86 & 156 & 67 & 89 \\
\hline & Stomachs with prey & 3 & 79 & 13 & 130 & 75 & 66 & 130 & 52 & 37 \\
\hline \multirow[t]{3}{*}{ All months (147) } & Fish collected & 562 & 2391 & 436 & 30,234 & 33,352 & 2007 & 3927 & 112 & 344 \\
\hline & Stomachs analyzed & 200 & 712 & 242 & 406 & 431 & 99 & 512 & 101 & 116 \\
\hline & Stomachs with prey & 139 & 447 & 121 & 325 & 362 & 77 & 400 & 78 & 48 \\
\hline
\end{tabular}


moved immediately after capture and preserved in formalin for laboratory analysis. In some months, tagging and releasing Striped Bass was a higher priority than determining stomach contents; therefore, all fishes captured were not available for diet analysis.

To account for size-related changes in habitat use (Able and Fahay, 2010), diet composition within species (Garrison and Link, 2000b), and interactions across species (Buckel and McKown, 2002), species were split into multiple size classes when data permitted: small (Summer Flounder: 200-300 $\mathrm{mm}$ total length [TL]; Weakfish: $80-200 \mathrm{~mm}$ TL; Bluefish: $55-300 \mathrm{~mm}$ fork length [FL]), medium (Summer Flounder: 301-400 mm TL; Weakfish: 201-350 $\mathrm{mm}$ TL), and large (Summer Flounder: 401-670 mm TL; Weakfish: 351-565 mm TL; Bluefish: 301-732 mm FL). For Striped Bass, a single size class was used because of limited sample sizes, the absence of prior evidence for ontogenetic shifts beyond the YOY stage (Walter et al., 2003), and the relatively large sizes of our specimens (422-920 $\mathrm{mm} \mathrm{FL).}$

\section{Diet analysis}

In the laboratory, preserved stomachs were carefully opened and the contents transferred to a solution of rose bengal stain and $95 \%$ ethyl alcohol. Prey items were identified to the lowest practical taxonomic level by using available keys and guides for the Mid-Atlantic region (Weiss, 1995; Able and Fahay, 1998) and enumerated. For each stomach, abundant or large prey types were sorted and placed on preweighed filter papers or aluminum weighing pans and dried to a constant weight $( \pm 0.0001 \mathrm{~g})$ in a drying oven $\left(70^{\circ} \mathrm{C}\right)$. Dry weights were chosen because they are more representative of nutritional value and have less weighing error than wet weights (Hyslop, 1980), especially for small or partial prey (Carr and Adams, 1972). For small and, therefore, hard-to-separate prey items (e.g., copepods and mysids), an aggregate sample was dried and the percent contribution by volume of different prey types was recorded and later converted to weights. Through the use of this protocol, prey-specific dry weights were obtained directly for larger prey or estimated from aggregate samples of smaller, mixed prey items for each stomach analyzed.

Trawl collections yielded "clusters" of individuals within species and size classes per location; therefore, the percent contribution by weight of prey items was calculated with the following cluster sampling estimator (Buckel et al., 1999a; 1999b; Gartland et al., 2006). For a given size class of a predator, the percent contribution by weight of each prey type $k\left(\% W_{\mathrm{k}}\right)$ to the diet was calculated with the following equation:

$$
\% W_{\mathrm{k}}=\frac{\sum_{\mathrm{i}=1}^{\mathrm{n}} M_{\mathrm{i}} q_{\mathrm{ik}}}{\sum_{\mathrm{i}=1}^{\mathrm{n}} M_{\mathrm{i}}} \cdot 100,
$$

$$
\text { where } \begin{aligned}
q_{\mathrm{ik}}= & \frac{W_{\mathrm{ik}}}{W_{\mathrm{i}}} ; \\
\mathrm{n}= & \text { the number of trawls; } \\
M_{\mathrm{i}}= & \text { the number of species size class sampled } \\
& \text { per tow } i ; \\
w_{\mathrm{i}}= & \text { the total dry weight of all prey in stomachs } \\
& \text { for that species size class in tow } I ; \text { and } \\
& w_{\mathrm{ik}}=\text { the total dry weight of prey type } k \\
& \text { in all stomachs for that species size class } \\
& \text { collected in tow } i .
\end{aligned}
$$

To facilitate analysis, prey items were grouped into the following general categories: squids (predominantly Loligo spp.), decapod crustaceans (including swimming crabs, sand crabs, rock crabs [Cancer borealis and C. irroratus], spider crabs, hermit crabs, decapod zoea, and shrimps [predominately Crangon septemspinosa and Palaemonetes sp.]), nondecapod crustaceans (including amphipods, isopods, cumaceans, mysids, and mantis shrimp), bivalves (clams and periwinkles), fishes (44 species identified), worms and wormlike organisms (nematodes, polychaetes, annelids, and leeches), and other unidentified (UID) items (inorganic matter, organic matter, eggs, and insects). In addition, prey items (species or higher taxa) that contributed on average $>5 \%$ by weight to the overall mean diet of a species size class were included as additional prey categories. Therefore, if Bay Anchovy (Anchoa mitchilli) composed $>5 \%$ of the diet for a given species size class in any month, it was included as a prey category and the category "fishes" represented all remaining fish prey that contributed $<5 \%$ to the diet of that species size.

The cumulative trophic diversity was calculated for each species size class to determine whether the sample sizes that were analyzed were sufficient to describe the diet of a given species size class in each month (Ferry and Cailliet, 1996; Cortés, 1997; Braccini et al., 2005; Belleggia et al., 2008). The Shannon-Wiener index $\left(H^{\prime}\right)$, which describes entropy on the basis of information theory, was calculated as each stomach that contained prey was added to the analysis for 100 randomizations of the data for each species size class:

$$
H^{\prime}=-\sum_{\mathrm{i}=1}^{\mathrm{S}}\left(p_{\mathrm{i}}\right) \cdot\left(\log _{\mathrm{c}} p_{\mathrm{i}}\right)
$$

where $S=$ the number of prey categories; and

$p_{\mathrm{i}}=$ the proportion of the cumulative (total) sample (gut contents) represented by the $i$ th prey category.

Following Jost (2006), $H^{\prime}$ was converted to effective number of species $\left(\exp \left(H^{\prime}\right)\right)$, a true diversity. Only groups (monthly species size classes) with mean trophic diversity curves that appeared asymptotic or with $>40$ sampled guts were included in the similarity analysis (described in the next paragraph).

To evaluate the degree of similarity in diets between species and size classes, nonmetric multidimensional scaling (nMDS) and hierarchical clustering were used 
within each month and across all months (PRIMER-E, Ltd., Plymouth, UK ${ }^{1}$ ). The nMDS data were calculated as the percentage of diet by weight for each month and each species-size-class combination and were log-transformed before use in the Bray-Curtis index to construct the sample similarity matrix. Group-average hierarchical clustering was then used to identify those predators that had dietary similarities at the $60 \%$ level following Jaworski and Ragnarsson (2006) and Clarke and Warwick (2001).

\section{Habitat and diet overlap}

Habitat and diet overlap between pairs of species size classes were determined through the use of Schoener's index (Schoener 1970). This index was calculated with this equation:

$$
\alpha=1-0.5\left(\sum_{\mathrm{i}=1}^{\mathrm{n}}|p i j-p i k|\right),
$$

which shows the overlap $(\alpha)$, where pij and pik are the proportions of the $i$ th resource (trawl station or prey proportion) used by species $j$ and $k$, respectively. Index values range from 0 to 1 , with values $>0.6$ representing biologically important overlap in resource use (Wallace, 1981; Buckel and McKown, 2002; Bethea et al., 2004).

\section{Results}

\section{Spatial distribution, abundance, and sizes}

The spatial distribution, abundance, and size distribution for each of the 4 predators were variable over the course of our 5-month study (Table 1, Figs. 2 and 3). Summer Flounder were the most consistently collected species throughout this study. They were distributed throughout our study area, with a slight shift in abundance from offshore to inshore in summer followed by the reverse in fall. The size distribution of Summer Flounder was relatively constant, with individuals of 206-670 mm TL representing a broad range of age classes (YOY to 4+) collected from June to October. Weakfish (80-565 mm TL) also were collected consistently, with greater abundances occurring inshore. Catches of Weakfish in June and July were dominated by larger size classes ( $>200 \mathrm{~mm} \mathrm{TL}$ ), with smaller size classes (YOY or $1+, \leq 200 \mathrm{~mm}$ TL) becoming abundant from August to October. Similarly, Bluefish (55-732 mm FL) were most abundant inshore. They were dominated by larger size classes ( $>300 \mathrm{~mm}$ FL) in June, with smaller size classes $(\leq 300 \mathrm{~mm}$ FL) becoming abundant inshore from July to October.

Striped Bass, which were typically larger $(422-920$ $\mathrm{mm}$ FL) than the other 3 species (Fig. 3), were less abundant and highly variable in time and space. In

\footnotetext{
${ }^{1}$ Mention of trade names or commercial companies is for identification purposes only and does not imply endorsement by the National Marine Fisheries Service, NOAA.
}

June and August, collections of Striped Bass were limited to the northernmost strata of the sample area. No Striped Bass were collected in July and September, likely because the northern strata were not sampled during those months. In October, Striped Bass were distributed throughout our study area. In all months in which they were collected, they were typically inshore.

\section{Diet analysis}

Because of limited or zero abundance of some species size classes in some months (described previously), sampling limitations, and the occurrence of empty stomachs, adequate food habit information was not obtained over all species size classes or months. The relative contributions of prey types to the diets for species size classes in each month are summarized in Table 2 (species size classes with insufficient samples sizes to be included in subsequent analyses are presented). For the groups that were considered adequately sampled for diet description (Fig. 4) and, therefore, included in the cluster analysis, the cumulative trophic diversity curves indicated that sample sizes of 30-40 guts were sufficient to characterize the diet in most cases. However, for some monthly species size classes (e.g., medium Weakfish in August and medium Summer Flounder in October) trophic diversity continued to increase beyond 40 guts analyzed.

Size-specific patterns in trophic diversity differed across species, with Summer Flounder showing decreased diversity with size in June. In contrast, larger size classes of Weakfish in August and Bluefish in October had more diverse diets than did smaller size classes of these species. Overall, diversity of prey items increased throughout time in Summer Flounder and Striped Bass, and it remained low for small Bluefish. Weakfish diet diversity also was relatively stable through the 5-month period of this study, with the exception of the high trophic diversity of the medium size class of this species in August.

Cluster analysis separated the size classes for each of the 4 species into 3 groups in June at the $60 \%$ similarity level (Fig. 5). The first group consisted of large (>400 mm TL) Summer Flounder, which preyed predominantly on squids $(88.1 \%)$ (Table 2$)$. Small and medium Summer Flounder formed the second group, and medium (201-350 mm TL) Weakfish the third. Although the second and third groups consumed mostly fishes (0-73.3\% sand lances [Ammodytes spp.] and 6.1$52.9 \%$ UID and other fishes), they were separated by the amounts of decapod crustaceans (2.1-20.9\%) and squids (8.3-21.5\%) in the former and mysids $(33.4 \%)$ in the latter.

In July, the cluster analysis identified 3 groups at the $60 \%$ similarity level from among the 4 species size classes for which enough data were available. Small and medium Summer Flounder were grouped together, with diets consisting of both pelagic and benthic prey, including Butterfish (Peprilus triacanthus; 15.8-18.7\%), 


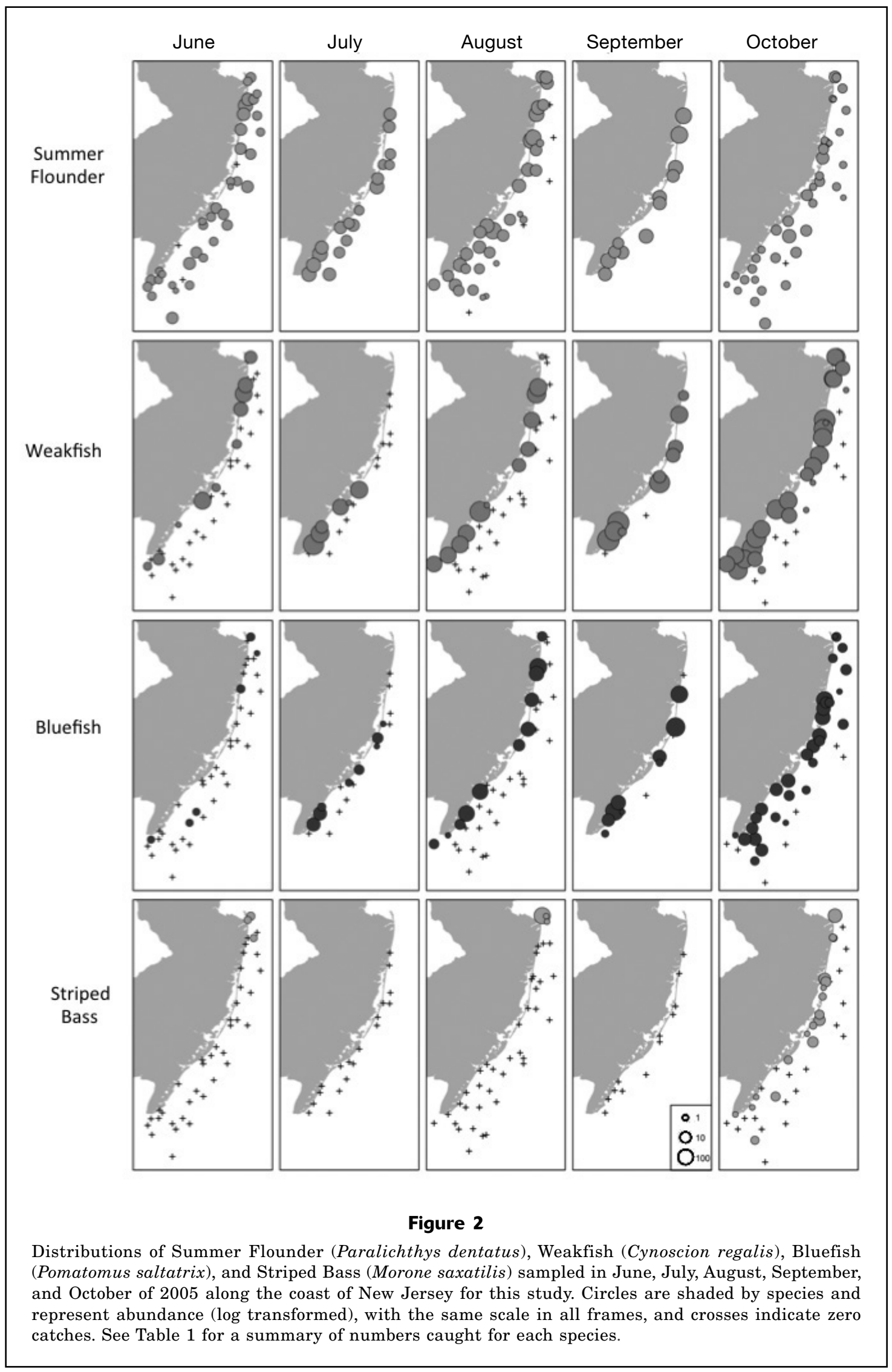




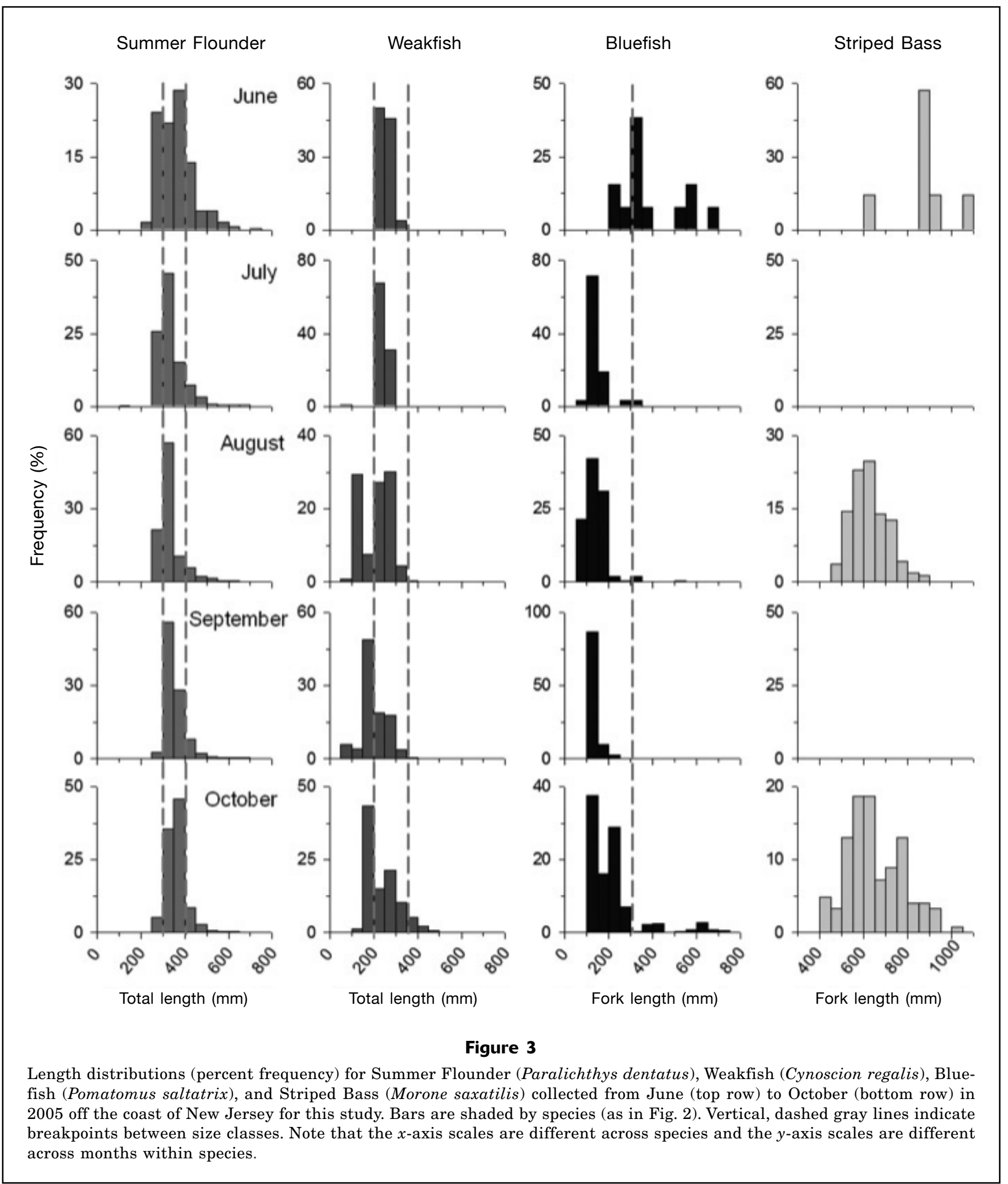


Table 2

Stomach contents of small, medium, and large Summer Flounder (Paralichthys dentatus), PdS, PdM, PdL; small, medium, and large Weakfish (Cynoscion regalis), CrS, CrM, CrL; small and large Bluefish (Pomatomus saltatrix), PsS, PsL; Striped Bass (Morone saxatilis), Ms, for this study of habitat and diet overlap of these 4 piscivorous fishes. All samples were collected in 2005 off the coast of New Jersey. Diet is summarized by month and for all months. $\% W_{\mathrm{k}}$ is the proportion of identifiable prey to the diet by weight. Note that proportions from cluster estimators do not add up to $100 \%$ in all cases (see main text for calculation). An asterisk (*) indicates groups with insufficient sample sizes for inclusion in the analysis with nonmetric multidimensional scaling. UID=unidentified.

\begin{tabular}{|c|c|c|c|c|c|c|c|c|c|c|c|c|c|c|c|c|c|c|c|c|c|c|c|}
\hline & & 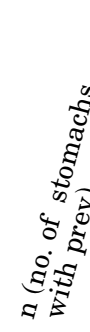 & 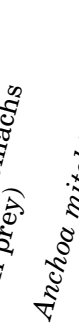 & 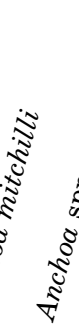 & 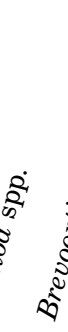 & 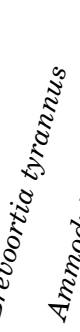 & 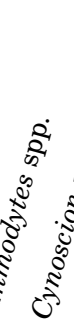 & 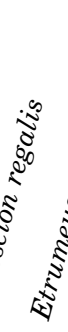 & 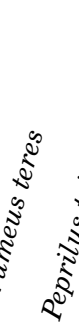 & 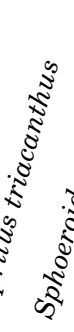 & 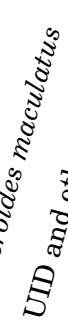 & 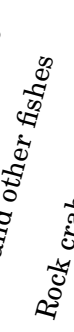 & $\frac{0}{0}$ & 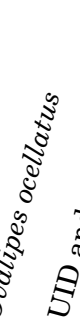 & 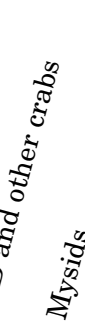 & क्ञ & ¿্ঠ & 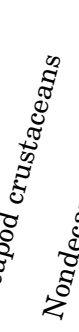 & 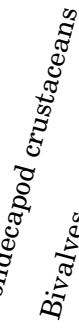 & $\frac{c^{2}}{3}$ & कृ & 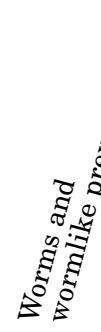 & 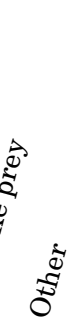 \\
\hline \multirow[t]{6}{*}{ Jun } & $\mathrm{CrM}$ & 42 & & & & & & & & & 52.9 & & & & 33.4 & 0.7 & 9.4 & 0.7 & & & & & 2.9 \\
\hline & $\mathrm{CrL}^{*}$ & 1 & & & & & & & & & & & & & & & 21.2 & & & & & & 78.8 \\
\hline & $\mathrm{PdS}$ & 30 & & & & 10.0 & & & & & 21.8 & 2.7 & & & 5.3 & & 20.9 & 9.7 & 3.3 & & 21.5 & & 1.7 \\
\hline & PdM & 42 & & 1.5 & & 73.3 & & & 0.8 & & 6.1 & 4.9 & & & $<0.1$ & $<0.1$ & 2.1 & 0.1 & & & 8.3 & & 2.8 \\
\hline & $\mathrm{PdL}$ & 26 & & 0.3 & & 10.3 & & & & & 0.1 & & & & & & 0.1 & & & & 88.1 & & 1.1 \\
\hline & $\mathrm{PsL}^{*}$ & 4 & & & & 94.0 & & & & & & & & & & & & & & & & & 6.0 \\
\hline \multirow[t]{6}{*}{ Jul } & CrM & 116 & 15.6 & 1.5 & & 0.9 & & & & & 4.2 & 0.1 & $\begin{array}{ll}1 & 1.7\end{array}$ & $7 \quad 1.6$ & 62.4 & 1.5 & 5.1 & 3.4 & & & & 0.5 & 1.3 \\
\hline & $\mathrm{PdS}$ & 39 & & & & 4.2 & 16.4 & & 18.7 & & 24.7 & 2.7 & $\begin{array}{ll}7 & 1.8\end{array}$ & 32.6 & 20.6 & 0.6 & 1.6 & 4.7 & & & & & 1.4 \\
\hline & $\mathrm{PdM}$ & 74 & 2.9 & & & 0.9 & & 9.8 & 15.8 & & 35.3 & 23.8 & $\begin{array}{ll}8 & 0.3\end{array}$ & 3.0 & 4.8 & 0.4 & 0.6 & $<0.1$ & 0.1 & & 1.4 & $<0.1$ & 0.7 \\
\hline & $\mathrm{PdL}^{*}$ & 12 & 1.4 & & & & & & 61.6 & & 24.3 & 9.5 & & & 1.9 & & & & & & 1.1 & & 0.1 \\
\hline & PsS & 18 & 29.9 & 31.3 & & & & & & & 38.8 & & & & & 0.1 & & & & & & & \\
\hline & $\mathrm{PsL}^{*}$ & 3 & & 19.1 & & & & & 52.6 & & 28.2 & & & & 0.1 & & & & & & & & \\
\hline \multirow[t]{9}{*}{ Aug } & $\mathrm{CrS}$ & 99 & 5.1 & 4.8 & & & & & & & 42.1 & & & 0.2 & 36.3 & 3.2 & 7.0 & 0.2 & & & & 0.2 & 0.9 \\
\hline & CrM & 84 & 7.6 & 10.0 & & & 23.5 & & & & 28.5 & & 1.2 & 1.6 & 16.3 & 8.0 & 0.8 & 0.2 & & & 0.2 & 2.0 & 0.2 \\
\hline & $\mathrm{CrL}^{*}$ & 5 & & 10.9 & & & & & & & 54.2 & & & 10.1 & 0.7 & 0.1 & & 0.1 & & & & & 24.0 \\
\hline & $\mathrm{Ms}$ & 11 & & & & & & & 2.2 & & 6.1 & & $<0.1$ & 0.2 & & $<0.1$ & 0.1 & 0.1 & 45.3 & & 0.6 & $<0.1$ & 0.1 \\
\hline & $\mathrm{PdS}$ & 64 & & 10.6 & & & & & 8.4 & & 21.5 & 0.4 & $\begin{array}{ll}4 & 7.9\end{array}$ & 4.7 & 37.9 & 4.0 & 2.8 & & 0.6 & & & & 0.7 \\
\hline & PdM & 178 & 2.5 & 0.8 & & & & 7.6 & 1.2 & & 41.0 & 11.8 & $\begin{array}{ll}8 & 6.2\end{array}$ & 4.3 & 19.7 & 0.1 & 0.3 & & 0.4 & 0.1 & 3.5 & & 0.3 \\
\hline & PdL & 62 & 1.4 & 0.6 & & & & 28.9 & 2.6 & & 29.7 & 6.4 & $\begin{array}{ll}4 & 0.1\end{array}$ & 0.7 & 0.7 & & 0.3 & & $<0.1$ & & 28.0 & & 0.5 \\
\hline & PsS & 105 & 56.3 & 19.3 & & & 9.5 & & 0.6 & & 12.3 & & & $<0.1$ & 0.5 & $<0.1$ & 0.3 & & & & 0.8 & & 0.5 \\
\hline & $\mathrm{PsL}^{*}$ & 17 & 29.7 & 0.2 & & & & & 0.4 & & 18.2 & & $<0.1$ & & & & & & 23.5 & & 4.2 & & 0.2 \\
\hline \multirow[t]{8}{*}{ Sep } & $\mathrm{CrS}$ & 96 & 20.5 & 8.7 & & & & & & & 33.4 & & & $<0.1$ & 33.5 & 0.4 & 1.4 & 0.2 & & & 0.8 & & 1.1 \\
\hline & CrM & 45 & 33.1 & 2.3 & & & & & & & 25.3 & & & & 34.5 & 0.1 & 4.1 & $<0.1$ & & & & 0.1 & 0.4 \\
\hline & $\mathrm{CrL}^{*}$ & 5 & 83.5 & & & & & & & & 1.7 & & & & 10.7 & & 4.1 & & & & & & \\
\hline & PdS* & 3 & & & & & & & & & 23.0 & & & & 77.0 & & & & & & & & \\
\hline & PdM & 74 & 17.8 & 10.4 & & & & 12.8 & 1.3 & & 13.4 & 13.7 & $\begin{array}{ll}7 & 2.3\end{array}$ & 1.6 & 13.2 & 0.4 & 2.5 & 7.2 & & & 1.7 & 0.2 & 1.7 \\
\hline & $\mathrm{PdL}^{*}$ & 8 & 5.0 & 11.5 & & & & 19.7 & & & 14.6 & 3.9 & & & & & & & & & 45.3 & & \\
\hline & PsS & 147 & 13.2 & 16.7 & & & & & & & 64.2 & & & & $<0.1$ & & & & & & 5.6 & 0.1 & 0.2 \\
\hline & $\mathrm{PsL}^{*}$ & $\begin{array}{ll}2 & 1\end{array}$ & 100.0 & & & & & & & & & & & & & & & & & & & & \\
\hline \multirow[t]{9}{*}{ Oct } & $\mathrm{CrS}$ & 130 & 10.2 & 2.9 & & & $<0.1$ & & & & 51.7 & & & 0.4 & 23.2 & 0.3 & 9.4 & 1.0 & & & & 0.2 & 0.7 \\
\hline & CrM & 75 & 3.8 & 0.5 & & 13.3 & & & & & 71.7 & & $<0.1$ & 0.1 & 2.8 & 3.7 & 1.0 & 0.6 & & & 2.0 & 0.1 & 0.3 \\
\hline & CrL & 66 & 0.5 & 0.2 & 20.7 & & & & & & 70.3 & & & 0.2 & $<0.1$ & 0.7 & 0.5 & 0.2 & & & 6.2 & & 0.4 \\
\hline & $\mathrm{Ms}$ & 37 & 16.0 & 0.3 & 10.1 & 0.5 & 6.9 & & & 19.2 & 29.0 & 2.7 & $\begin{array}{ll}7 & 8.2\end{array}$ & 1.0 & & 0.3 & 1.8 & 2.6 & 0.1 & & 0.9 & & 0.2 \\
\hline & PdS* $^{*}$ & 3 & & & & & & & & & 23.6 & & 6.2 & 2.2 & 34.9 & & 30.9 & & & & & & 2.2 \\
\hline & $\mathrm{PdM}$ & 79 & 13.3 & 4.7 & & 2.3 & 9.5 & & 1.3 & & 43.1 & 1.7 & $\begin{array}{ll}7 & 0.4\end{array}$ & 0.3 & 13.2 & 0.9 & 0.3 & 1.1 & & & 6.6 & $<0.1$ & 1.3 \\
\hline & $\mathrm{PdL}^{*}$ & 13 & 1.9 & & & & 26.7 & & & & 26.7 & 0.7 & & & $<0.1$ & & & & & & 44.0 & & $<0.1$ \\
\hline & PsS & 130 & 30.1 & 3.8 & 1.3 & & 2.8 & & 2.6 & & 46.8 & & & & $<0.1$ & & $<0.1$ & 0.1 & & & 12.1 & & 0.3 \\
\hline & PsL & 52 & 15.5 & & 7.2 & & 25.2 & & 4.0 & 6.7 & 35.3 & & & & & & & & & & 5.0 & & 1.1 \\
\hline & $\mathrm{CrS}$ & 325 & 11.4 & 4.8 & & & $<0.1$ & & & & 45.0 & & & 0.3 & 28.9 & 1.0 & 6.9 & 0.6 & & & 0.2 & 0.2 & 0.8 \\
\hline \multirow[t]{8}{*}{ months } & $\mathrm{CrM}$ & 362 & 10.7 & 3.4 & & 5.0 & 6.2 & & & & 40.3 & $<0.1$ & $\begin{array}{ll}1 & 0.7\end{array}$ & 70.8 & 23.6 & 3.8 & 2.6 & 1.0 & & & 0.8 & 0.7 & 0.6 \\
\hline & CrL & 77 & 1.1 & 0.6 & 19.8 & & & & & & 69.2 & & & 0.5 & 0.1 & 0.7 & 0.5 & 0.2 & & & 5.9 & & 1.3 \\
\hline & $\mathrm{Ms}$ & 48 & 8.3 & 0.2 & 5.3 & 0.2 & 3.6 & & 1.1 & 10.0 & 18.0 & 1.4 & $\begin{array}{ll}4 & 4.3\end{array}$ & 0.6 & & 0.1 & 0.9 & 1.4 & 21.8 & & 0.8 & $<0.1$ & 0.1 \\
\hline & $\mathrm{PdS}$ & 139 & & 4.8 & & 3.4 & 4.7 & & 9.2 & & 22.6 & 1.5 & $\begin{array}{ll}5 & 4.2\end{array}$ & 2.9 & 26.9 & 2.0 & 6.7 & 3.5 & 1.0 & & 4.7 & & 1.1 \\
\hline & PdM & 447 & 7.8 & 3.6 & & 16.8 & 3.2 & 4.3 & 2.6 & & 29.7 & 8.3 & $\begin{array}{ll}3 & 1.8\end{array}$ & 3.5 & 10.9 & 0.4 & 1.0 & 1.4 & 0.1 & $<0.1$ & 5.1 & $<0.1$ & 1.4 \\
\hline & PdL & 121 & 1.0 & 0.7 & & 4.2 & 4.8 & 10.9 & 2.3 & & 16.5 & 2.7 & $7<0.1$ & 0.2 & 0.3 & & 0.2 & & $<0.1$ & & 55.4 & & 0.6 \\
\hline & PsS & 400 & 33.5 & 8.7 & 0.9 & & 3.8 & & 1.9 & & 41.7 & & & $<0.1$ & 0.1 & $<0.1$ & 0.1 & 0.1 & & & 9.0 & $<0.1$ & 0.3 \\
\hline & PsL & 78 & 17.0 & 0.1 & 6.4 & 0.4 & 22.2 & & 3.7 & 6.0 & 33.3 & & $<0.1$ & & $<0.1$ & & & & 2.6 & & 4.8 & & 1.0 \\
\hline
\end{tabular}




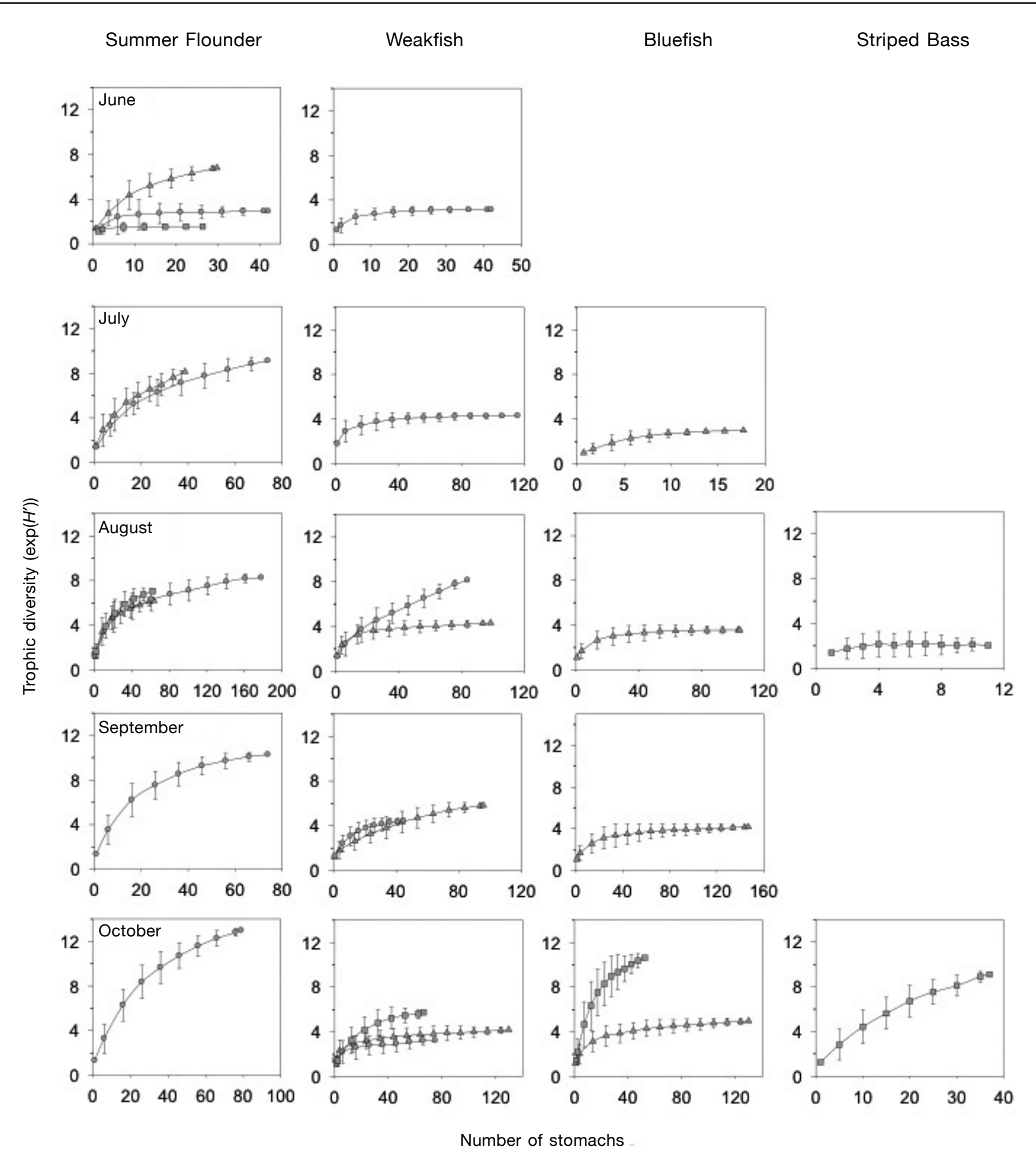

Figure 4

Trophic diversity $\left(\exp \left(H^{\prime}\right)\right)$ as a function of the number of stomachs analyzed for Summer Flounder (Paralichthys dentatus), Weakfish (Cynoscion regalis), Bluefish (Pomatomus saltatrix), and Striped Bass (Morone saxatilis), collected from June (top row) to October (bottom row) in 2005 off the coast of New Jersey. Plotted are the means of 100 randomizations for a selected number of stomachs (error bars indicate \pm 1 standard deviation). Lines with triangles, circles, or squares indicate results for small, medium, or large size classes, respectively. Note that the $x$-axis scales are different across species. 


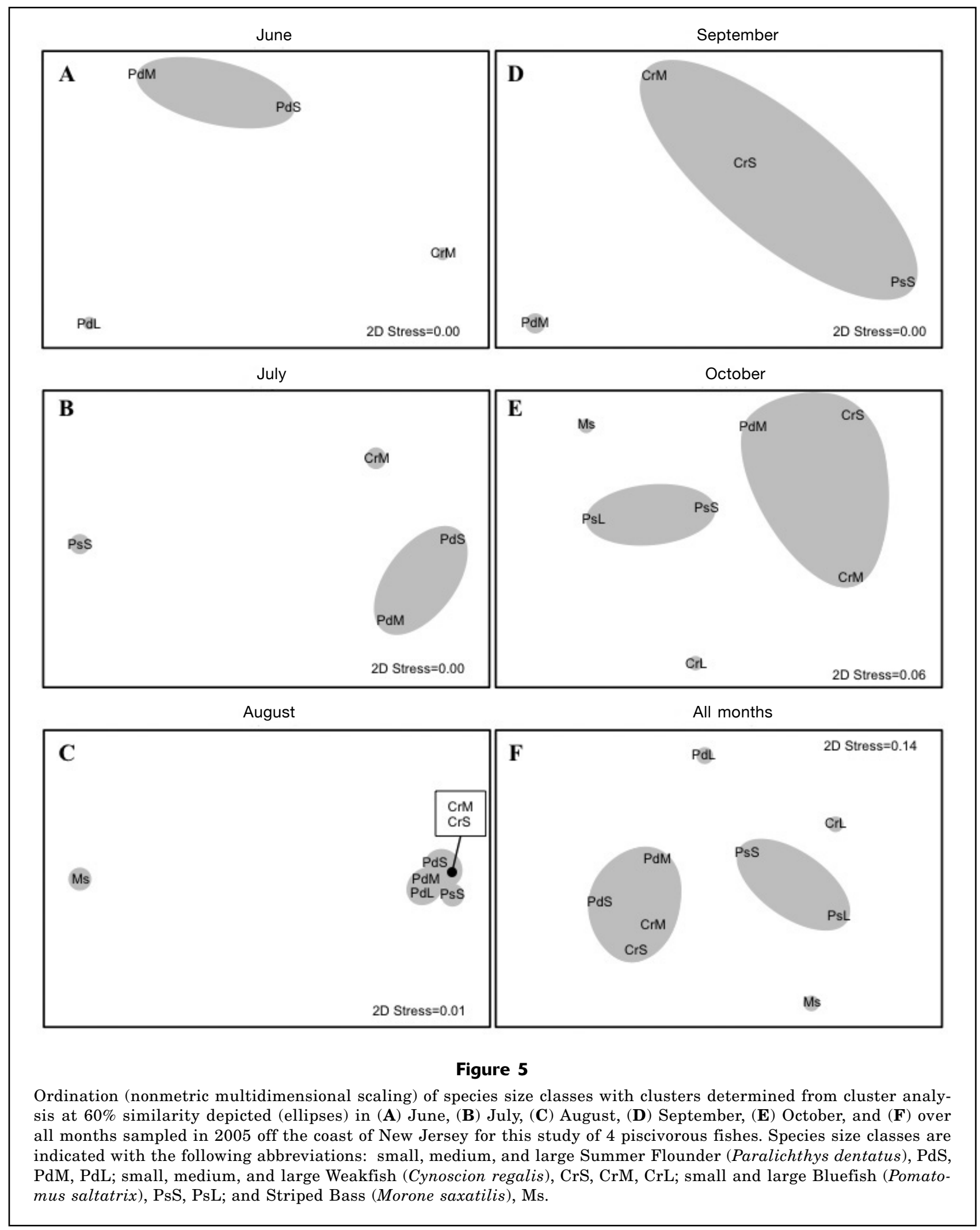


mysids (4.8-20.6\%), rock crabs (2.7-23.8\%), and large amounts of UID and other fishes (24.7-35.3\%). About $10 \%$ of medium Summer Flounder diet in July was composed of pelagic Round Herring (Etrumeus teres), and small Summer Flounder consumed a substantial amount of Weakfish. Medium Weakfish formed their own group with a diet consisting largely of mysids (62.4\%) and anchovies (Bay Anchovy and Anchoa spp.; $17.1 \%)$, and decapod crustaceans were also present (5.1\%). Small Bluefish also formed their own group, feeding principally on 2 prey types: anchovies (61.2\%) and UID and other fish species $(38.8 \%)$.

Four groups were identified at $60 \%$ similarity by the cluster analysis in August, 2 with broad diets, 1 intense piscivore, and 1 bivalve consumer. The first broad diet group included medium and large Summer Flounder, which consumed varying amounts of UID fishes (29.7-41.0\%), squids (3.5-28.0\%), Round Herring (7.6-28.9\%), mysids (0.7-19.7\%), rock crabs (6.4-11.8\%), and ocellate lady crab (Ovalipes ocellatus; $0.1-6.2 \%)$. The second broad diet group, consisting of medium and small Weakfish and small Summer Flounder, also consumed large amounts of UID and other fishes (21.5-42.1\%). However, this group differed from the previous group in the consumption of mysids (16.3-37.9\%), shrimps (3.2-8.0\%), ocellate lady crab (0-7.9\%), decapod crustaceans $(0.8-7.0 \%)$, anchovies (9.9-17.6\%), Weakfish (0-23.5\%), and Butterfish (0$8.4 \%)$. Although cannibalism by medium Weakfish was substantial (23.5\%) during this month, Weakfish were not detected in the diets of small Weakfish or small Summer Flounder. Small Bluefish, with a diet of anchovies $(75.6 \%)$, Weakfish $(9.5 \%)$, and UID and other fishes $(12.3 \%)$, made up the piscivore group. Striped Bass, composing the fourth group in August, consumed mostly bivalves $(45.3 \%)$ and some UID and other fish species were present $(6.1 \%)$.

In September, the cluster analysis identified 2 groups at the $60 \%$ similarity level from the 4 species size classes with enough data. The first group, consisting of medium and small Weakfish and small Bluefish, consumed varying amounts of anchovies (29.3-35.4\%), mysids $(<1-34.5 \%)$, and UID and other fish species (25.3-64.2\%). Medium Summer Flounder made up the second group and differed from the previous group by displaying a more diverse diet that included rock crabs (13.7\%), mysids (13.2\%), Round Herring (12.8\%), and nondecapod crustaceans $(7.2 \%)$ in addition to anchovies $(28.2 \%)$.

In October, 4 groups were identified, along with UID and other fish species as the primary diet component for each of them. The first group, consisting of small and medium Weakfish and medium Summer Flounder, differed from the rest primarily in the amounts of prey consumed: anchovies (4.3-18.0\%), mysids (2.8-23.2\%), sand lances (0-13.3\%), Weakfish (0-9.5\%), UID and other fishes (43.1-71.7\%), decapod crustaceans $(0.3-9.4 \%)$, and squids (0-6.6\%). The second group, composed of small and large Bluefish, preyed on a variety of fish species, including anchovies (15.5-33.9\%), Atlantic Menhaden (Brevoortia tyrannus; 1.3-7.2\%), Butterfish (2.6-4.0\%), Northern Puffer (Sphoeroides maculatus; $0-6.7 \%)$, Weakfish $(2.8-25.2 \%)$, UID and other fishes (35.3-46.8\%), and squids (5.0-12.1\%). Large Weakfish formed the third group and consumed primarily Atlantic Menhaden (20.7\%), with large amounts of UID and other fishes $(70.3 \%)$, and a lesser amount of squids $(6.2 \%)$. Striped Bass, the final group, consumed ocellate lady crab $(8.2 \%)$ and a variety of fish species: Atlantic Menhaden (10.1\%), Bay Anchovy (16.0\%), Northern Puffer (19.2\%), Weakfish (6.9\%), and UID and other fishes (29.0\%). Cannibalism among Weakfish was not prevalent in this month, although all other species consumed Weakfish to some degree.

When the data are aggregated across months, 1 multispecies group, 1 single-species group, and 3 groups, each of a single-species and single-size, emerge. The multispecies group consisted of small and medium Weakfish and small and medium Summer Flounder, with large and small Bluefish composing the single species group. The multispecies group consumed anchovies $(4.8-16.2 \%)$, sand lances (0-16.8\%), Weakfish $(<0.1-6.2 \%)$, butterfish $(0-9.2 \%)$, UID and other fishes (22.6-45.0\%), mysids (10.9-28.9\%), rock crabs $(0-8.3 \%)$, decapod crustaceans $(1.0-6.9 \%)$, and squids $(0.2-5.1 \%)$. Large and small Bluefish also consumed a variety of fishes-Atlantic Menhaden (0.9-6.4\%), anchovies (17.1-42.2\%), Northern Puffer (0-6.0\%), Weakfish (3.8-22.2\%), UID and other fish species (33.3-41.7\%) and squids (4.8-9.0\%) but consumed less mysids, rock crabs, and decapod crustaceans than did the multispecies group. Large Summer Flounder, the third group, consumed a mix of squids (55.4\%) and fishes, mostly Round Herring (10.9\%) and UID and other fish species $(16.5 \%)$. The fourth group, large Weakfish, preyed mainly upon Atlantic Menhaden (19.8\%), UID and other fish species $(69.2 \%)$, and squids (5.9\%). Striped Bass formed the final group, with a diet of bivalves (21.8\%) and fishes: Bay Anchovy (8.3\%), Atlantic Menhaden $(5.3 \%)$, Northern Puffer (10.0\%), UID and other fish species $(18.0 \%)$.

\section{Habitat and diet overlap indices}

Monthly overlap ( $\alpha$ from Schoener's index) in habitat and diet for each pair of predators (species size classes) indicated shared use of resources $(\alpha>0)$; however, $\alpha$ was below the biologically important level of 0.6 in most months (Fig. 6). Some groups had substantial overlap ( >0.6) in habitat but not diet (e.g., large, medium, and small Summer Flounder). There also were instances of overlap $(>0.6)$ in diet but not habitat (e.g., small Weakfish versus medium Weakfish and small Summer Flounder). There were no cases where substantial overlap ( $>0.6$ ) in both habitat and diet occurred at the same time. For many of the pairwise comparisons, overlaps in both habitat and diet increased severalfold during the fall in this 5-month study, from levels of $\sim 0.2$ in 


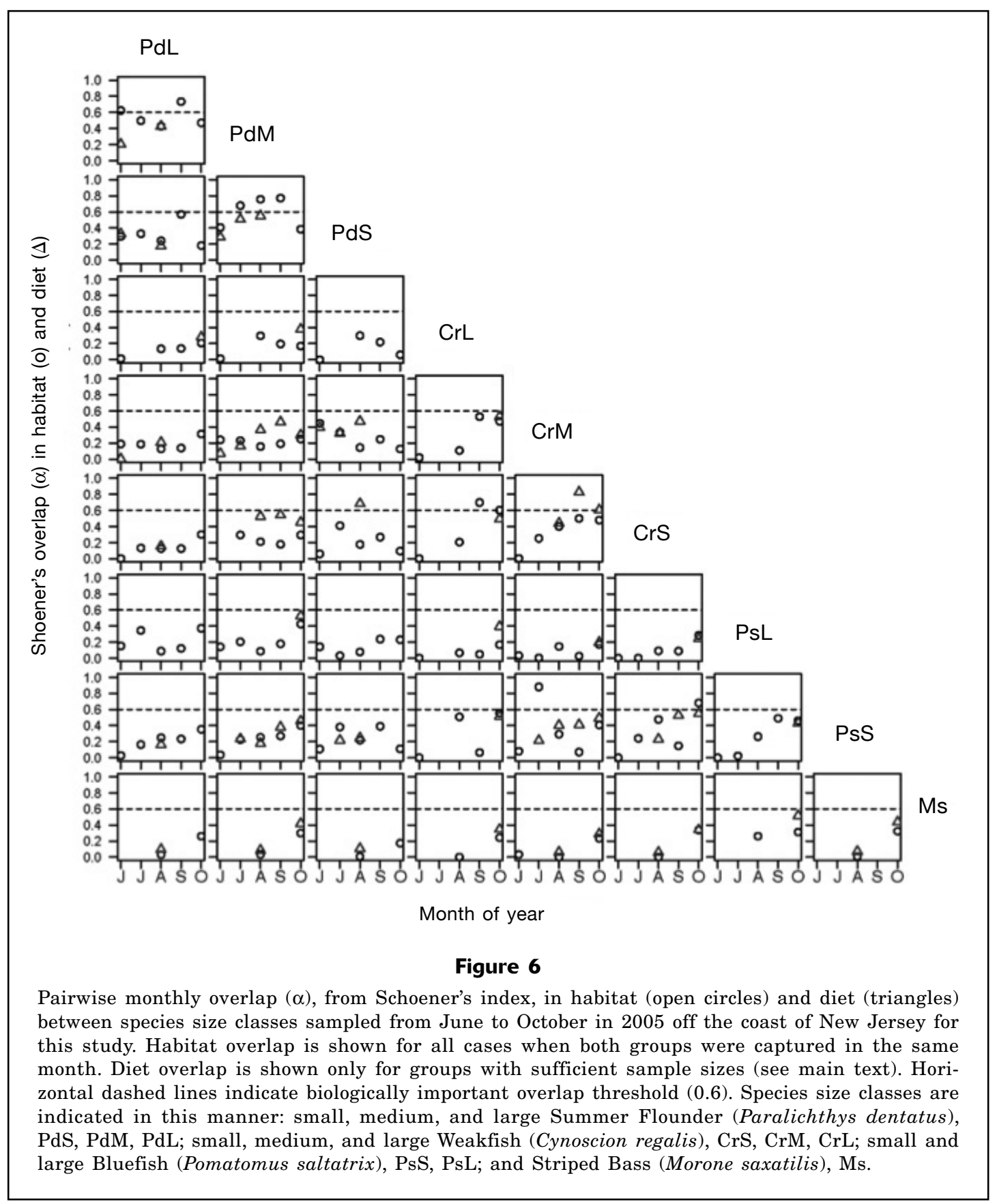

June and July to levels $>0.4$ in September and October. Small and medium Weakfish had relatively high overlap in diet, but lower overlap in habitat, with small and medium Summer Flounder from August to October. The limited spatial distribution of Striped Bass, in addition to their absence during some months, resulted in a low degree of overlap in habitat with groups of other species, but Striped Bass were most abundant in the fall and, therefore, overlapped with the other predators at that time.

\section{Discussion}

The degree of habitat and diet overlap among Summer Flounder, Weakfish, Bluefish, and Striped Bass varied with size and season. The size classes of these 4 predators examined in our study exhibited different patterns in spatial distribution, depth, and habitat use. Summer Flounder were most evenly distributed throughout our study area-a pattern also observed in a longer (1982-2003) time series of sampling at generally deep- 
er depths (from 27 to $>193 \mathrm{~m}$ ) (Able and Fahay, 2010), with similar sizes present during our 5-month study on the inner continental shelf. Weakfish in our study occurred primarily inshore in shallow strata. Their abundance increased through the summer because of the appearance of YOY fish, and they dominated the catch by October-a trend also observed in composite collections over time on the deeper continental shelf (Able and Fahay, 2010).

The size structure of Bluefish was similarly variable with multiple YOY cohorts appearing during summer and eventually dominating the proportion of catch by October. Bluefish were concentrated at inshore, shallow stations, as had been documented previously (Able et al., 2003; Wiedenmann and Essington, 2006; Wuenschel et al., 2012). In October, the distribution of Bluefish was more uniform with depth, and they appeared to utilize a greater portion of the inner continental shelf during the period of southward migration, as was evident from other composite sampling at similar and deeper depths (Able and Fahay, 2010).

Bluefish and Weakfish distributions indicated a high degree of similarity in their use of the inshore shelf during the summer months. In contrast, the distribution of Striped Bass was limited to the northernmost stations during summer. Like Bluefish, Striped Bass were more abundant throughout the study area during their fall migration (October). The limited collections of Striped Bass, coupled with a priority to tag and release them during certain months, restricted our ability to describe Striped Bass diets. Nevertheless, Striped Bass showed little overlap in habitat use with the other predators studied.

The species-level distributions and monthly size frequencies tended to overestimate overlap because different sizes may have occupied different locations in a given month. When viewed at the size-class level, spatial (habitat) overlap was rarely above 0.6. Similarly, assessment of diet overlap at the species level (i.e., combining size classes and ignoring ontogenetic shifts in diet) would likely increase perceived overlap. For example, large and medium Summer Flounder diet overlap was moderate $(\alpha \sim 0.2-0.5)$ and overlap between medium and small sizes was similarly variable ( $\alpha \sim 0.3-0.6)$, but overlap between large and small Summer Flounder was much lower $(\alpha \sim 0.2-0.3)$. This result supports the interpretation of gradual ontogenetic changes in diet and some similarity between adjacent size classes. Use of a single size group for Striped Bass because of limited sample sizes prevented the exploration of ontogenetic shifts for this species, which were significant in one study (Smith and Link, 2010) but not another (Walter et al., 2003). Regardless of potential ontogenetic differences, their extensive use of estuaries in New Jersey and throughout their range during many seasons (Able and Fahay, 2010) probably also contributes to the limited co-occurrence of this species with the other species size classes studied.
Unidentified fish remains were large components of the diet for many of the species size classes in our study-a common problem encountered in the analysis of stomach contents (Garrison and Link, 2000a; 2000b). The presence of large portions of UID fishes serves to increase the overlap in diet and decrease the number of distinct clusters from the groups analyzed. Assuming that identifiable and unidentifiable prey occur in similar relative proportions, we consider the separation of distinct groupings in our analysis to be conservative. Where diets between species size classes showed little overlap, we can conclude diets were indeed different.

The diets of Summer Flounder, Weakfish, Bluefish, and Striped Bass on the inner continental shelf of New Jersey during summer varied month to monthan observation that could not be obtained from previous studies conducted in the region across a greater portion of the shelf region over multiple years (Garrison and Link, 2000b; Link et al., 2002; Walter et al., 2003; Buckel et al., 2009; Smith and Link, 2010). The finer scale in our study accounts for the slightly different patterns of similarity among Summer Flounder, Weakfish, Bluefish, and Striped Bass diets in comparison with results that had been reported previously for the shelf ecosystem of the northeastern United States (Garrison and Link, 2000b). Although the size classes differed slightly, this previous study reported Summer Flounder $(21-70 \mathrm{~cm})$ and Bluefish $(>31 \mathrm{~cm})$ in a piscivore guild distinct from small Bluefish $(10-30 \mathrm{~cm})$ and Weakfish $(10-50 \mathrm{~cm})$.

On a much finer spatial scale, we observed greater overlap in diets, which varied through time, between Summer Flounder and Weakfish, particularly for the small and medium size classes. This similarity was driven by large amounts of mysids and other crustaceans in the diet. Both Summer Flounder and Weakfish incorporated more fishes and squids in their diet as they increased in size. The early onset of piscivory by Bluefish separated them from the smaller size classes of Summer Flounder and Weakfish. Together, these differences relative to earlier studies point out the advantages of the finer temporal, spatial, and size-class scales used in this study.

Of the 4 predators analyzed from the Mid-Atlantic region in our study, only Weakfish were consumed in appreciable numbers by the other species. Weakfish were consumed by small Summer Flounder (16.5\%) in July and small Bluefish (9.5\%) in August, and an appreciable amount of cannibalism by medium-size Weakfish (23.5\%) was observed in August. In October, large Bluefish and Summer Flounder fed extensively on Weakfish (25.2-26.7\%), with medium and small Summer Flounder and Striped Bass also consuming Weakfish but in lesser proportions. Similarly, in Long Island bays, YOY Bluefish and Summer Flounder consumed Weakfish (7.5\% and $3.0 \%$ by weight, respectively); however, data were reported across sizes and seasons (spring, summer, and fall), and Weakfish diet was not investigated 
(Sagarese et al., 2011). Predation on juvenile Weakfish has also been observed in Delaware Bay by adult Weakfish and Summer Flounder (Taylor, 1987).

A recent synopsis of diets documented across the continental shelf in the region indicated that Weakfish occurred at relatively low levels $(\sim 5 \%)$ in diets of Bluefish, Summer Flounder, and Weakfish (Smith and Link, 2010). Although direct predation on Weakfish by the 4 piscivores investigated was high at different times during our study, large numbers of Weakfish were also collected in our surveys, indicating high availability of this prey type. However, the possibility that the high degree of predation may influence the continuing low population levels of Weakfish $\left(\mathrm{NEFSC}^{2}\right)$ needs further study, especially because some of these predators, such as Summer Flounder (Able et al., 2011) and Striped Bass, have reached high population levels in recent years $\left(\mathrm{ASMFC}^{3}\right)$.

Another prey species, Atlantic Menhaden, has received increased attention because of its historical importance as the main prey of Striped Bass at other locations during other times (Nelson et al., 2003; Walter et al., 2003; Overton et al., 2008). Uphoff (2003) suggested that a shortage of Atlantic Menhaden as prey for Striped Bass in the Chesapeake Bay may have reduced the nutritional condition of those Striped Bass in the 1990s, making them susceptible to disease. In our study, there was little evidence of Atlantic Menhaden in the diets of any of these predators except in October when Striped Bass, Weakfish, and Bluefish consumed them to some degree, although Atlantic Menhaden are typically present in the area during the other months (Ahrenholz, 1991; Smith, 1999). Adult Atlantic Menhaden occur along the coast in summer (Smith, 1999), but YOY Atlantic Menhaden reside in estuaries in summer and are not plentiful in the ocean until October (Able and Fahay, 2010), when they appeared in the diets of the piscivores examined in our study. Adult Atlantic Menhaden exceed the gape limitation for most of the species size classes examined, except that for Striped Bass and large Bluefish; therefore, it is not surprising that little consumption of this species was documented in summer. Diet analyses for larger predator species and larger individuals of those species considered in our study are needed to fully evaluate consumption of large Atlantic Menhaden in the Middle Atlantic Bight.

As with our study, Woodland and Secor (2011) reported no clupeids in the diet of YOY Bluefish collected

\footnotetext{
${ }^{2}$ NEFSC (Northeast Fisheries Science Center). 2009. 48th Northeast Regional Stock Assessment Workshop (48th SAW) Assessment Report. U.S. Dept. Commer., Northeast Fish. Sci. Cent. Ref. Doc. 09-15, 834 p. [Available from National Marine Fisheries Service, 166 Water Street, Woods Hole, MA 02543-1026 or http://www.nefsc.noaa.gov/nefsc/publications/.]

3 ASMFC (Atlantic States Marine Fisheries Commission). 2011. Striped Bass Stock Assessment Update 2011, 207 p. Prepared by the Striped Bass Stock Assessment Subcommittee and Striped Bass Tagging Subcommittee. [Available from http://www.asmfc.org/speciesDocuments/stripedBass/reports/stockassmts/2011StripedBassAssmtUpdate.pdf.]
}

on the inner continental shelf off Maryland in August, although clupeids made up $9 \%$ of the diet of YOY Bluefish collected in Chesapeake Bay in the same month. However, Atlantic Menhaden contributed a large portion to Bluefish diets, but less so for Summer Flounder in Long Island bays (Sagarese et al., 2011), and large proportions to the diets of Weakfish, Bluefish, and Sandbar Shark (Carcharhinus plumbeus) in Delaware Bay (Taylor, 1987), underscoring the importance of Atlantic Menhaden as prey in estuaries during summer. Additionally, we acknowledge that the degree of consumption and overlap in diets may vary with the population size of the predators. At the time of our study, the populations of Striped Bass $\left(\mathrm{ASMFC}^{3}\right)$ and Summer Flounder (Able et al., 2011; Terceiro, 2011) were relatively high and the populations of Bluefish (Shepherd and Nieland ${ }^{4}$ ) and Weakfish $\left(\right.$ NEFSC $\left.^{2}\right)$ were relatively low. More detailed estimates of population-level consumption with more diet information from larger size classes would help to determine the direct effect of the predation of these piscivores on Weakfish and Atlantic Menhaden populations.

One behavioral attribute that may reduce resource overlap between these predators is their use of the water column. Recent studies have indicated that a presumed benthic species, Summer Flounder, may spend considerable time in the water column (Yergey, 2011; Henderson, 2012). This observation is consistent with the surprisingly large proportion of pelagic prey in their diets and their ability to feed in the water column in the laboratory (Olla et al., 1972). In addition, aggregation of diet data across the $24 \mathrm{~h}$ cycle may obscure some interactions with prey that undergo diel migrations (e.g., mysids and Summer Flounder; Buchheister and Latour, 2011). Although sampling was limited to daylight hours, given that gut evacuation rate generally decreases with fish size (Wuenschel and Werner, 2004) and with the relatively slow passage of food in carnivores (Smith, 1989; Adams and Breck, 1990), the results of our study capture much of the nighttime feeding habits of the predators examined.

Another caveat to consider when evaluating overlap in habitat between these species is that overlap may be confounded by the length of a tow with a relatively large net. Although the duration of tows was short in our study, the distance covered $(\sim 1.85 \mathrm{~km})$ may have included multiple discrete habitats, inflating assessments of overlap. However, the overlap estimates were not systematically high and the area covered per tow was very small relative to the overall study area and to the distances that the species examined are known to move; therefore, analysis at the tow level is appropriate.

This study has described in fine spatial and temporal detail the degree of overlap in habitat and diet

\footnotetext{
${ }^{4}$ Shepherd, G. R., and J. Nieland. 2010. Bluefish 2010 stock assessment update. U.S. Dept. Commer., Northeast Fish. Sci. Cent. Ref. Doc. 10-15, 33 p. [Available from National Marine Fisheries Service, 166 Water Street, Woods Hole, MA 02543-1026 or http://www.nefsc.noaa.gov/nefsc/publications/.]
} 
of 4 piscivores on the inner continental shelf off New Jersey from summer through fall. It does not consider these parameters on adjacent estuaries where these species can also be abundant (Able and Fahay, 2010). For example, Striped Bass are known to use estuaries in the region during the summer (Tupper and Able, 2000; Able and Grothues, 2007; Ferry and Mather, 2012). The same is true for Bluefish (Grothues and Able, 2007; Sagarese et al., 2011), Summer Flounder (Sackett et al., 2007; 2008; Sagarese et al., 2011), and Weakfish (Taylor, 1987; Turnure 2010). Therefore, our findings from the inner shelf should be viewed with this qualification in mind. As an example, the diets described here for inshore waters revealed differences in diets, compared with diets observed in studies carried out within estuaries (Gartland et al., 2006; Latour et al., 2008; Sagarese et al., 2011).

Although not necessarily unexpected given differences in prey availability between estuarine and ocean habitats, these differences in diets underscore the need to incorporate into ecosystem models both distribution and diet information from the inner shelf and adjacent estuaries because of connectivity between them, especially over seasonal scales (Able, 2005). These data have typically been lacking. Many prey categories were shared by the piscivores examined in our study on the inner continental shelf, but different patterns in habitat use (in time and space) seemed to alleviate overlap between these predators for prey. However, overlaps in fish distributions and diets increased during fall as species left estuaries and underwent coastal migrations. Therefore, the information on spatial distributions and food habits reported here at finer spatial and temporal scales, compared to results from previous studies, complements and provides a critical link between what is known about these mobile, seasonally migratory predators within estuaries and about these same piscivores across larger geographic scales (e.g., the northeastern shelf of the United States). It is reasonable to ask whether diet overlap may continue to increase during winter when many of these predators are concentrated farther south and likely co-occur in thermal refuges in the South Atlantic Bight.

\section{Conclusions}

Results from this study, at finer temporal, spatial, and size-class scales than have been attempted typically in other studies, indicate that overlap in distribution on the inner continental shelf for the 4 piscivores examined was not uniform through time and that they had moderate levels of overlap in diet. The exception was observed in the fall, when many of these species became concentrated as both larger individuals and smaller YOY fishes left estuaries, gathered with other individuals on the inner shelf, and began their southward migration as temperatures cooled. Given the high seasonal variability in water temperature and produc- tivity in the system studied and the migratory nature of the species investigated, it is not surprising that habitat use and species interactions were variable.

Our understanding of species interactions on the inner continental shelf has been limited, in the past, by the gap between sampling programs within estuaries and bays and programs occurring farther offshore. The intensive monthly sampling of this study on the inner continental shelf revealed the dynamic nature of habitat and diet overlap for Summer Flounder, Weakfish, Bluefish, and Striped Bass. The use of inner shelf resources by these 4 important species had previously been poorly defined. The limited degree of resource overlap in summer and the increasing overlap in fall for the 4 piscivores indicate that this period of changeable overlap may be important for the population dynamics of these species and that information about it should be incorporated into not only species-specific models of population dynamics but also broader ecosystem-level models.

\section{Acknowledgments}

This study was funded through a grant from the collaborative Bluefish/Striped Bass Dynamics Research Program of Rutgers University and the National Marine Fisheries Service. The authors thank New Jersey Department of Environmental Protection personnel (L. Barry, A. Mazzarella and S. Reap), the staff at the Rutgers University Marine Field Station and Captain S. Cluett and crew of the RV Seawolf for assistance. The following individuals provided field and laboratory assistance: R. Nichols, M. Greaney, J. Conwell, J. Lamonaca, J. Eppenstiener, and J. Bunkiewicz. B. Smith, S. Rowe, and anonymous reviewers provided constructive comments on the manuscript. We are grateful to all of the above. This article is contribution no. 2013-3 from the Institute of Marine and Coastal Sciences, Rutgers University.

\section{Literature cited}

Able, K. W.

2005. A reexamination of fish estuarine dependence: evidence for connectivity between estuarine and ocean habitats. Estuar. Coast. Shelf Sci. 64:5-17

Able, K. W., and M. P. Fahay.

1998. The first year in the life of estuarine fishes in the Middle Atlantic Bight, 342 p. Rutgers Univ. Press, New Brunswick, NJ.

2010. Ecology of estuarine fishes: temperate waters of the western North Atlantic, 584 p. Johns Hopkins Univ. Press, Baltimore.

Able, K. W., and T. M. Grothues.

2007. Diversity of estuarine movements of striped bass (Morone saxatilis): a synoptic examination of an estuarine system in southern New Jersey. Fish. Bull. 105:426-435. 
Able, K. W., P. Rowe, M. Burlas, and D. Byrne. 2003. Use of ocean and estuarine habitats by young-ofyear bluefish (Pomatomus saltatrix) in the New York Bight. Fish. Bull. 101:201-214.

Able, K. W., M. C. Sullivan, J. A. Hare, G. Bath-Martin, J. C. Taylor, and R. Hagan.

2011. Larval abundance of summer flounder (Paralichthys dentatus) as a measure of recruitment and stock status. Fish. Bull. 109:68-78.

Adams, S. M., and J. E. Breck.

1990. Bioenergetics. In Methods for fish biology (C. B. Schreck, and P. B. Moyle, eds.), p. 389-415. Am. Fish. Soc., Bethesda, MD.

Ahrenholz, D. W.

1991. Population biology and life history of the North American menhadens, Brevoortia spp. Mar. Fish. Rev. 53:3-19.

Andrews, K. S., and C. J. Harvey.

2013. Ecosystem-level consequences of movement: seasonal variation in the trophic impact of a top predator. Mar. Ecol. Prog. Ser. 473:247-260.

Belleggia, M., E. Mabragana, D. E. Figueroa, L. B. Scenna, S.

A. Barbini, and J. M. Diaz de Astarloa.

2008. Food habits of the broadnose skate, Bathyraja brachyurops (Chondrichthyes, Rajidae), in the southwest Atlantic. Sci. Mar. 72:701-710.

Bellgraph, B. J., C. S. Guy, W. M. Gardner, and S. A. Leathe. 2008. Competition between saugers and walleyes in nonnative sympatry. Trans. Am. Fish. Soc. 137:790-800.

Bethea, D. M., J. A. Buckel, and J. K. Carlson.

2004. Foraging ecology of the early life stages of four sympatric shark species. Mar. Ecol. Prog. Ser. 268:245-264.

Braga, R. R., H. Bornatowski, and J. R. S. Vitule.

2012. Feeding ecology of fishes: an overview of worldwide publications. Rev. Fish Biol. Fish. 22:915-929.

Braccini, J. M., B. M. Gillanders, and T. I. Walker.

2005. Sources of variation in the feeding ecology of the piked spurdog (Squalus megalops): implications for inferring predator-prey interactions from overall dietary composition. ICES J. Mar. Sci. 62:1076-1094.

Buchheister, A., and R. J. Latour.

2011. Trophic ecology of summer flounder in lower Chesapeake Bay inferred from stomach content and stable isotope analyses. Trans. Am. Fish. Soc. 140:1240-1254.

Buckel, J. A., and K. A. McKown.

2002. Competition between juvenile striped bass and bluefish: resource partitioning and growth rate. Mar. Ecol. Prog. Ser. 234:191-204.

Buckel, J. A., D. O. Conover, N. D. Steinberg, and K. A. McKown.

1999a. Impact of age-0 bluefish (Pomatomus saltatrix) predation on age- 0 fishes in the Hudson River estuary: evidence for density-dependent loss of juvenile striped bass (Morone saxatilis). Can. J. Fish. Aquat. Sci. 56:275-287.

Buckel, J. A., M. J. Fogarty, and D. O. Conover.

1999b. Foraging habits of bluefish, Pomatomus saltatrix, on the U.S. east coast continental shelf. Fish. Bull. 97:758-775.

1999c. Mutual prey of fish and humans: a comparison of biomass consumed by bluefish, Pomatomus saltatrix, with that harvested by fisheries. Fish. Bull. 97:776-785.
Buckel, J. A., J. P. Pessutti, J. E. Rosendale, and J. S. Link. 2009. Interactions between bluefish and striped bass: behavior of bluefish under size- and number-impaired conditions and overlap in resource use. J. Exp. Mar. Biol. Ecol. 368:129-137.

Byrne, D.

1994. Stock assessment of New Jersey's nearshore recreational fisheries resources. In Proceedings of the workshop on the collection and use of trawl survey data for fisheries management; Charleston, SC, 15-17 August (T. Berger, ed.), p. 36-42. Atlantic States Mar. Fish. Comm., Washington, D.C.

Carr, W. E. S., and C. A. Adams.

1972. Food habits of juvenile marine fishes: evidence of the cleaning habit in the leatherjacket, Oligoplites saurus, and the spottail pinfish, Diplodus holbrooki. Fish. Bull. 70:1111-1120.

Clarke, K. R., and R. M. Warwick.

2001. Change in marine communities: an approach to statistical analysis and interpretation, $2^{\text {nd }}$ ed., $172 \mathrm{p}$. PRIMER-E Ltd., Plymouth, UK.

Cortés, E.

1997. A critical review of methods of studying fish feeding based on analysis of stomach contents: application to elasmobranch fishes. Can. J. Fish. Aquat. Sci. 54:726-738.

Elliot, M., and K. L. Hemingway (eds.).

2002. Fishes in estuaries, 636 p. Blackwell Science Ltd., Oxford, UK.

Ferry, L. A., and G. M. Cailliet.

1996. Sample size and data analysis: are we characterizing and comparing diet properly? In "Gutshop '96:" feeding ecology and nutrition in fish symposium proceedings, International Congress on the Biology of Fishes; San Francisco, 14-18 July (D. MacKinley and K. Shearer, eds.), p. 71-80. Am. Fish. Soc., Bethesda, MD.

Ferry, K. H., and M. E. Mather.

2012. Spatial and temporal diet patterns of subadult and small adult striped bass in Massachusetts estuaries: data, a synthesis, and trends across scales. Mar. Coast. Fish. 4:30-45.

Garrison, L. P., and J. S. Link.

2000a. Diets of five hake species in the northeast United States continental shelf ecosystem. Mar. Ecol. Prog. Ser. 204:243-255.

2000b. Dietary guild structure of the fish community in the Northeast United States continental shelf ecosystem. Mar. Ecol. Prog. Ser. 202:231-240.

Gartland, J., R. J. Latour, A. D. Halvorson, and H. M. Austin. 2006. Diet composition of young-of-the-year bluefish in the lower Chesapeake Bay and the coastal ocean of Virginia. Trans. Am. Fish. Soc. 135:371-378.

Grothues, T. M., and K. W. Able.

2007. Scaling acoustic telemetry of bluefish in an estuarine observatory: detection and habitat use patterns. Trans. Am. Fish. Soc. 136:1511-1519.

Heithaus, M. R., A. Frid, A. J. Wirsing, and B. Worm.

2008. Predicting ecological consequences of marine top predator declines. Trends Ecol. Evol. 23:202-210.

Henderson, M. J.

2012. Movements, growth, and mortality of Chesapeake Bay summer flounder based on multiple tagging technologies. Ph.D. diss., 262 p. College of William \& Mary, Williamsburg, VA. 
Hyslop, E. J. 1980. Stomach contents analysis - a review of methods and their application. J. Fish Biol. 17:411-429.

Jaworski, A., and S. A. Ragnarsson

2006. Feeding habits of demersal fish in Icelandic waters: a multivariate approach. ICES J. Mar. Sci. 63:1682-1694.

Jost, L.

2006. Entropy and diversity. Oikos 113:363-375.

Latour, R. J., J. Gartland, C. F. Bonzek, and R. A. Johnson. 2008. The trophic dynamics of summer flounder (Paralichthys dentatus) in Chesapeake Bay. Fish. Bull. 106:47-57.

Link, J. S.

2002. Ecological considerations in fisheries management: when does it matter? Fisheries 27:10-17.

Link, J. S., K. Bolles, and C. G. Milliken. 2002. The feeding ecology of flatfish in the northwest Atlantic. J. Northwest Atl. Fish. Sci. 30:1-17.

Myers, R. A., and B. Worm.

2003. Rapid worldwide depletion of predatory fish communities. Nature 423:280-283.

Nelson, G. A., B. C. Chase, and J. Stockwell.

2003. Food habits of striped bass (Morone saxatilis) in coastal water of Massachusetts. J. Northwest Atl. Fish. Sci. 32:1-25.

Olla, B. L., C. E. Samet, and A. L. Studholme.

1972. Activity and feeding behavior of the summer flounder (Paralichthys dentatus) under controlled laboratory conditions. Fish. Bull. 70:1127-1136.

Overholtz, W. J., and J. S. Link.

2007. Consumption impacts by marine mammals, fish, and seabirds on the Gulf of Maine-Georges Bank Atlantic herring (Clupea harengus) complex during the years 1977-2002. ICES J. Mar. Sci. 64:83-96.

Overholtz, W. J., J. S. Link, and L. E. Suslowicz. 2000. Consumption of important pelagic fish and squid by predatory fish in the northeastern USA shelf ecosystem with some fishery comparisons. ICES J. Mar. Sci. 57:1147-1159.

Overton, A. S., C. S. I. Manooch, J. W. Smith, and K. Brennan. 2008. Interactions between adult migratory striped bass (Morone saxatilis) and their prey during winter off the Virginia and North Carolina Atlantic coast from 19942007. Fish. Bull. 106:174-182.

Persson, L., P. Bystrom, E. Wahlstrom, J. Andersson, and J. Hjelm.

1999. Interactions among size-structured populations in a whole-lake experiment: size- and scale-dependent processes. Oikos 87:139-156.

Rudershausen, P. J., J. A. Buckel, J. Edwards, D. P. Gannon, C. M. Butler, and T. W. Averett

2010. Feeding ecology of blue marlins, dolphinfish, yellowfin tuna, and wahoos from the North Atlantic Ocean and comparison with other oceans. Trans. Am. Fish. Soc. 139:1335-1359.

Sackett, D. K., K. W. Able, and T. M. Grothues.

2007. Dynamics of summer flounder, Paralichthys dentatus, seasonal migrations based on ultrasonic telemetry. Estuar. Coast. Shelf Sci. 74:119-130

2008. Habitat dynamics of summer flounder, Paralichthys dentatus, within a shallow USA estuary, based on multiple approaches using acoustic telemetry. Mar. Ecol. Prog. Ser. 364:199-212.
Sagarese, S. R., R. M. Cerrato, and M. G. Frisk.

2011. Diet composition and feeding habits of common fishes in Long Island bays, New York. Northeast. Nat. 18:291-314.

Schoener, T. W.

1970. Nonsynchronous spatial overlap of lizards in patchy habitats. Ecology 51:408-418.

Schmitz, O. J.

2007. Predator diversity and trophic interactions. Ecology 88:2415-2426.

Smith, B. E., and J. S. Link.

2010. The trophic dynamics of 50 finfish and 2 squid species on the northeast US continental shelf. NOAA Tech. Memo. NMFS-NE-216, 640 p.

Smith, J. E.

1999. Distribution of Atlantic menhaden, Brevoortia tyrannus, purse-seine sets and catches from southern New England to North Carolina, 1985-96. NOAA Tech. Rep. NMFS 144, 22 p.

Smith, L. S.

1989. Digestive functions in teleost fishes. In Fish nutrition, $2^{\text {nd }}$ ed. (J. E. Halver, ed.), p. 332-423. Academic Press, San Diego, CA

Sutton, T. M., and J. J. Ney.

2002. Trophic resource overlap between age-0 striped bass and largemouth bass in Smith Mountain Lake, Virginia. N. Am. J. Fish. Manage. 22:1250-1259.

Taylor, E. T.

1987. Food habits of dominant piscivorous fishes in Delaware Bay, with special reference to predation on juvenile weakfish. M.S. thesis, 82 p. Univ. Delaware, Graduate College of Marine Studies, Lewes, DE.

Terceiro, $\mathrm{M}$

2011. The summer flounder chronicles II: new science, new controversy, 2001-2010. Rev. Fish Biol. Fish. 21:681-712.

Tupper, M., and K. W. Able.

2000. Movements and food habits of striped bass (Morone saxatilis) in Delaware Bay (USA) salt marshes: comparison of a restored and a reference marsh. Mar. Biol. 137: 1049-1058.

Turnure, J. T.

2010. Estuarine habitat ecology of adult weakfish $(C y$ noscion regalis): a multi-scale approach. M.S. thesis, 125 p. Rutgers Univ., New Brunswick, NJ.

Uphoff, J. H., Jr.

2003. Predator-prey analysis of striped bass and Atlantic menhaden in upper Chesapeake Bay. Fish. Manage. Ecol. 10:313-322.

Wallace, R. K., Jr.

1981. An assessment of diet-overlap indexes. Trans. Am. Fish. Soc. 110:72-76.

Walter, J. F., III, A. S. Overton, K. G. Ferry, and M. E. Mather 2003. Atlantic coast feeding habits of striped bass: a synthesis supporting a coast-wide understanding of trophic biology. Fish. Manage. Ecol. 10:349-360.

Weiss, H. M.

1995. Marine animals of southern New England and New York: identification keys to common nearshore and shallow water macrofauna. State Geological and Natural History Survey of Connecticut, Department of Environmental Protection. Bulletin 115, 344 p.

Wiedenmann, J., and T. E. Essington.

2006. Density-dependent overwinter survival in youngof-year bluefish (Pomatomus saltatrix)? A new approach for assessing stage-structured survival. Can. J. Fish. Aquat. Sci. 63:1934-1943. 
Woodland, R. J., and D. H. Secor.

2011. Differences in juvenile trophic niche for two coastal fish species that use marine and estuarine nursery habitats. Mar. Ecol. Prog. Ser. 439:241-254.

Woodland, R. J., D. H. Secor, and M. A. Wedge.

2011. Trophic resource overlap between small elasmobranchs and sympatric teleosts in Mid-Atlantic Bight nearshore habitats. Estuaries Coasts 34: 391-04.

Wuenschel, M. J., K. W. Able, J. A. Buckel, J. W. Morley, T. Lankford, A. C. Branson, D. O. Conover, D. Drisco, A. Jordaan, K. Dunton, D. H. Secor, R. J. Woodland, F. Juanes, and D. Stormer.
2012. Recruitment patterns and habitat use of young-ofthe-year bluefish along the United States east coast: insights from coordinated coastwide sampling. Rev. Fish. Sci. 20:80-102.

Wuenschel, M. J., and R. G. Werner.

2004. Consumption and gut evacuation rate of laboratory-reared spotted seatrout (Sciaenidae) larvae and juveniles. J. Fish Biol. 65:723-743.

Yergey, M. S.

2011. Movement of summer flounder (Paralichthys dentatus): application of telemetry to understanding ecology and bycatch discard mortality. M.S. thesis, 69 p. Rutgers Univ., New Brunswick, NJ. 